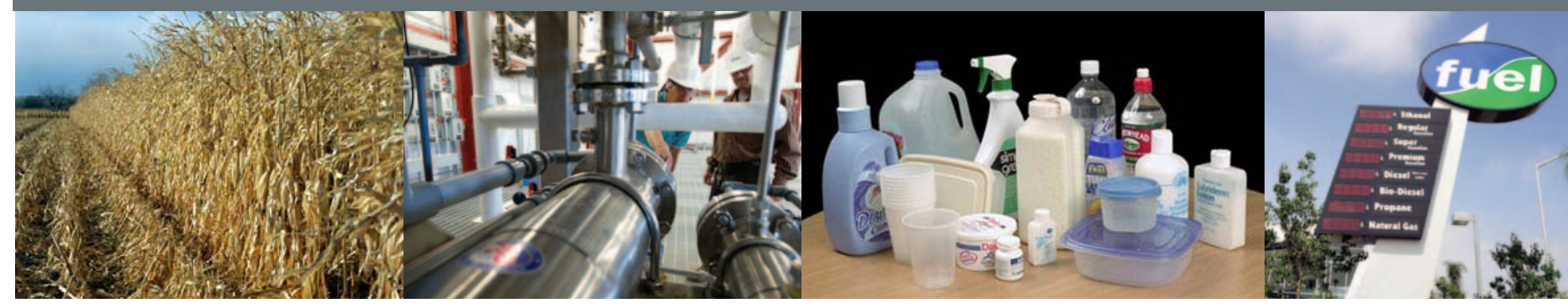

\title{
Partnering with Industry to Advance Biofuels and Bioproducts
}

For more than 30 years, the U.S. Department of Energy's (DOE) National Renewable Energy Laboratory (NREL) has been at the leading edge of research and technology advancements to develop renewable fuels and bioproducts. NREL works to develop cost-competitive alternatives to conventional transportation fuels and value-added biobased chemicals that can be used to manufacture clothing, plastics, lubricants, and other products.

NREL is developing technologies and processes to produce a range of sustainable, energy-dense advanced biofuels that are compatible with our existing transportation fuel infrastructure. As part of that effort, NREL's National Bioenergy Center has entered into more than 90 collaborations in the past five years with companies ranging in size from start-ups to those that appear on Fortune magazine's Fortune 100 list.

The new Integrated Biorefinery Research Facility (IBRF) showcases NREL's commitment to collaboration and to meeting the nation's biofuels and bioproducts development and deployment goals. Designed to speed the growth of the biofuels and bioproducts industries, the IBRF is a unique $\$ 33.5$ million pilot facility capable of supporting a variety of projects.

The IBRF is available to industry partners who work with NREL through cooperative research and development, technical, and analytical service agreements. With $27,000 \mathrm{ft}^{2}$ of high bay space, the IBRF provides industry partners with the opportunity to operate, test, and develop their own biorefining technology and equipment.

\section{Research Flexibility}

The IBRF offers an unprecedented level of research flexibility. In particular, it can handle a wide range of biomass feedstocks and pretreatment processes. Parallel pretreatment processing trains allow for the testing of conversion processes using a variety of technologies under a wide range of conditions.
The IBRF can handle high concentrations of solids in the pretreatment and enzymatic hydrolysis steps, a key factor in reducing costs. Bioreactors from $10 \mathrm{~L}$ to $9000 \mathrm{~L}$ and separation and concentration equipment are housed in the IBRF allowing for biomass conversion processes to be fully integrated.

\section{Access to Experts}

While using the IBRF, industry partners have access to NREL's world-renowned experts, process equipment, and systems that can be used to develop and evaluate commercial processes for the production of biobased products and fuels. In addition, partners have access to NREL's state-of-the-art molecular biology, biochemistry, and biomass compositional analysis laboratories. Advanced biofuels produced in the IBRF can be tested and analyzed in NREL's fuel testing laboratories, and data generated in the IBRF can be incorporated into technoeconomic and life cycle analysis models to estimate the feasibility and sustainability of commercial-scale production.

Ultimately, by leveraging the investments DOE has made in the IBRF and NREL, industry partners can develop conversion processes and technologies faster and enter biofuels and bioproducts markets sooner and more profitably.

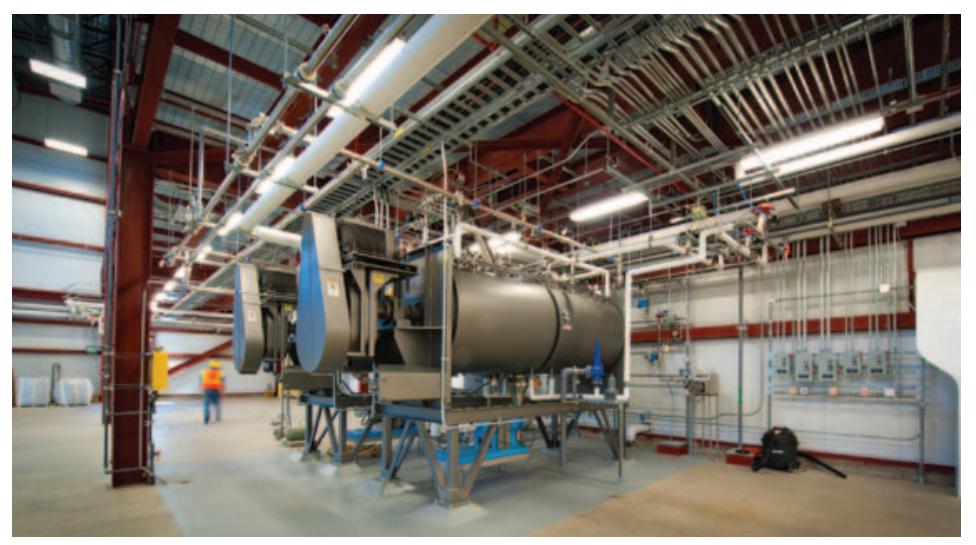

The IBRF's new enzymatic hydrolysis reactors can handle high solids a key factor in reducing conversion costs. 


\section{Pretreatment Capabilities}

- Continuous 1-ton/day vertical pretreatment reactor system with multiple reactors

- Residence times: 5-100 minutes, temperature range: $120^{\circ}-210^{\circ} \mathrm{C}$, Hastelloy C-2000 construction

- Optional secondary reactor allows for lower severity pretreatment $\left(120^{\circ}-180^{\circ} \mathrm{C}\right)$ and extended residence times

- Ability to test and evaluate different pretreatment schemes and catalysts (dilute acid, alkali, or hot water)

- Continuous 1-ton/day horizontal pretreatment reactor system with the capability for multiple configurations

- Residence times: 3-120 minutes, temperature range: $150^{\circ}-210^{\circ} \mathrm{C}$, Hastelloy C-2000 and 316 stainless steel construction

- Ability to test and evaluate different pretreatment schemes and catalysts (dilute acid, alkali, or hot water)

- Continuous 1-ton/day vertical pretreatment reactor system

- Residence times: 1-45 minutes, temperature range: $150^{\circ}-200^{\circ} \mathrm{C}$, zirconium construction

- Continuous 200-kg/day (dry basis) horizontal-screw pretreatment reactor system

- Residence times: 3-30 minutes, temperature range: $130^{\circ}-200^{\circ} \mathrm{C}$, Hastelloy $\mathrm{C}-2000$ construction

- 4-L batch steam gun pretreatment reactor system

\section{Enzymatic Hydrolysis and Fermentation}

- High-solids 4000-L horizontal paddle-type reactors

- Operate at total solids loading $>20 \%(\mathrm{w} / \mathrm{w})$

- Operate in batch mode with 36-hour turnaround time to achieve semi-continuous processing temperature range $40^{\circ}-75^{\circ} \mathrm{C}$

- Systems for injecting neutralizing chemicals and enzymes

- Bioreactors (continuous or batch/aerobic or anaerobic)

- Multiple stirred bioreactor systems from 10-L - 100-L

- Two 160 L stirred vessels; two 1,500-L stirred vessels; four 9,000-L stirred vessels

- Feed and support vessels (stirred) ranging in size from 100-L - 9,000-L

\section{Downstream Processing Equipment}

- 10-m-tall by $0.5-\mathrm{m}$-diameter sieve tray distillation column

- Continuous forced recirculation evaporator for concentrating or evaporative operations

- Small 1-L solid-bowl high-speed centrifuge $(17,000 \mathrm{G})$ for cell recovery

- Continuous sterilizable high-performance decanter (5,000 G) with 100 -L/hour capacity

- Continuous decanting centrifuge $(3,000 \mathrm{G})$ with 1,200-L/ hour capacity

- Semi-automatic perforated basket centrifuge (900 G) with automatic feed, discharge, and washing capability

- Semi-continuous pressure belt filter

- Continuous sterilizer

- Continuous ultrafiltration/reverse-osmosis system

\section{Other Capabilities}

- Compositional analysis

- Wet chemistry and near-infrared spectroscopy

- High performance liquid chromatography and spectrometers (infrared, visible, and ultraviolet)

\section{- Pilot plant monitoring}

- Real time data acquisition and dedicated mass spectrometer for on-line monitoring of fermentation exhaust gas composition

- Molecular biology laboratories

- Development of enzymes and biocatalysts

- Strain engineering

- Proteomics

- Transcriptomics

- Metabolomics

For additional information about the IBRF, including inquiries about equipment, capabilities, or partnership opportunities, please contact John Ashworth at 303-384-6858, john.ashworth@nrel.gov or Richard Bolin at 303-384-7716, richard.bolin@nrel.gov.

National Renewable Energy Laboratory

1617 Cole Boulevard, Golden, Colorado 80401

303-275-3000 • www.nrel.gov

NREL/FS-5100-53429 • December 2011

NREL is a national laboratory of the U.S. Department of Energy

Office of Energy Efficiency and Renewable Energy

Operated by the Alliance for Sustainable Energy, LLC

Printed with a renewable-source ink on paper containing at least

$50 \%$ wastepaper, including $10 \%$ post consumer waste. 